\title{
Nitric Oxide Decreases Stability of mRNAs Encoding Soluble Guanylate Cyclase Subunits in Rat Pulmonary Artery Smooth Muscle Cells
}

\author{
Galina Filippov, ${ }^{\star \ddagger}$ Donald B. Bloch, ${ }^{\star \ddagger}$ and Kenneth D. Bloch ${ }^{\star \ddagger}$ \\ *Cardiovascular Research Center and the Arthritis Unit of the General Medical Services, Massachusetts General Hospital; \\ and ${ }^{\ddagger}$ Department of Medicine, Harvard Medical School, Charlestown, Massachusetts 02129
}

\begin{abstract}
Nitric oxide stimulates soluble guanylate cyclase (sGC) to convert GTP to the intracellular second messenger cGMP. In rat pulmonary artery smooth muscle cells, $\mathrm{sGC}$ is an obligate heterodimer composed of $\alpha 1$ and $\beta 1$ subunits. We investigated the effect of NO donor compounds on sGC subunit gene expression in rat pulmonary artery smooth muscle cells. Sodium nitroprusside and $S$-nitroso-glutathione decreased sGC subunit mRNA and protein levels, as well as sGC enzyme activity. 1H-[1,2,4]oxadiazolo[4,3-a]quinoxalin-1-one, an sGC inhibitor, blocked the effect of sodium nitroprusside on sGC subunit gene expression, whereas 8-bromo cGMP decreased subunit mRNA levels, demonstrating that NO-mediated decrease in SGC subunit mRNA levels is cGMP-dependent. sGC subunit mRNA levels decreased more rapidly in rat pulmonary artery smooth muscle cells exposed to NO than in cells exposed to actinomycin D, suggesting that NO decreases SGC subunit mRNA stability. Actinomycin D and cycloheximide blocked the ability of NO to decrease sGC subunit mRNA levels. These results demonstrate that NO decreases $\mathrm{SGC}$ subunit mRNA stability via a transcription- and translation-dependent mechanism. ( $J$. Clin. Invest. 1997. 100:942-948.) Key words: cGMP • NOdonor compound - actinomycin D - cycloheximide - receptor
\end{abstract}

\section{Introduction}

Nitric oxide, the active moiety of endothelium-derived relaxing factor, has a critical role in the regulation of vascular tone and patency (reviewed in reference 1). NO regulates vascular cell proliferation, migration, and apoptosis. In addition, NO inhibits platelet and leukocyte activation. NO also participates in nonvascular functions including neurotransmission and the response to infection. Excessive NO production contributes to cellular injury and the hemodynamic sequelae of sepsis (2). Extensive research has been directed toward identifying the mechanisms regulating the production of NO. However, mech-

Address correspondence to Kenneth D. Bloch, M.D., Cardiovascular Research Center, CNY 4, Massachusetts General Hospital, 149 13th Street, Charlestown, MA 02129. Phone: 617-724-9540; FAX: 617-7265806; E-mail: blochk@helix.mgh.harvard.edu

Received for publication 19 June 1996 and accepted in revised form 22 May 1997.

J. Clin. Invest.

(c) The American Society for Clinical Investigation, Inc. 0021-9738/97/08/0942/07 \$2.00

Volume 100, Number 4, August 1997, 942-948

http://www.jci.org anisms regulating responsiveness to $\mathrm{NO}$ are less well characterized.

$\mathrm{NO}$ acts in part by stimulating soluble guanylate cyclase (sGC), ${ }^{1}$ which converts GTP to cyclic GMP (cGMP). cGMP is an intracellular second messenger that activates cGMP-dependent protein kinase, as well as other cGMP receptor proteins (3), resulting in diverse effects including relaxation of vascular smooth muscle. sGC is a heterodimer composed of $\alpha$ and $\beta$ subunits with two isoforms of each subunit encoded in the rat genome: $\alpha 1, \alpha 2, \beta 1$, and $\beta 2$ (4). $\alpha 1$ and $\beta 1$ subunits are the predominant isoforms in the lung and vascular smooth muscle cells (reference 5 and our unpublished data).

Increasing evidence suggests that NO modulates gene expression. NO regulates gene transcription via both cGMPdependent and -independent mechanisms. Peunova and Enikolopov (6) found, in rat pheochromocytoma PC12 cells, that the NO-mediated increase in c-fos gene expression was calcium- and cGMP-dependent and appeared to involve protein kinase A activation of the CREB transcription factor. Pilz et al. (7) observed, in rodent fibroblast and epithelial cell lines, that NO and a membrane-permeable cGMP analogue activated gene transcription via cis-acting nucleotide sequences containing a phorbol ester-response element. In contrast, Kourembanas et al. (8) found in endothelial cells that NO-mediated suppression of endothelin 1 and platelet-derived growth factor B chain gene transcription was cGMP independent. Similarly, DeCatarina et al. (9) and Shin et al. (10) reported that NO, but not cGMP analogues, inhibited transcription of genes encoding vascular cell adhesion molecule- 1 and intercellular adhesion molecule-1 in endothelial (9) and smooth muscle (10) cells, possibly by stabilizing the nuclear factor $-\kappa \mathrm{B}$ inhibitor, I $\mathrm{I} \mathrm{B} \alpha(11)$. NO can also modulate gene expression by altering mRNA stability. Pantopoulos and Hentze observed that NO stabilized transferrin receptor mRNA by activating binding of the iron-regulatory protein to iron-response elements located in the $3^{\prime}$ untranslated region of the mRNA (12).

To investigate the effect of chronic exposure to $\mathrm{NO}$ on $\mathrm{NO} /$ cGMP signal transduction, sGC subunit mRNA and protein levels and sGC enzyme activity were measured in cultured rat pulmonary artery smooth muscle cells (RPaSMC) exposed to chemical compounds that generate NO. Evidence is presented that chronic exposure to NO decreases sGC enzyme activity by decreasing the stability of the mRNAs encoding its subunits and that destabilization of $\mathrm{sGC}$ subunit mRNAs is dependent on gene transcription and protein synthesis.

1. Abbreviations used in this paper: GSNO, S-nitroso-glutathione; ODQ, 1H-[1,2,4]oxadiazolo[4,3-a]quinoxalin-1-one; RPaSMC, rat pulmonary artery smooth muscle cells; sGC, soluble guanylate cyclase; SNAP, $S$-nitroso-acetylpenicillamine; SNP, sodium nitroprusside. 


\section{Methods}

These investigations were approved by the Subcommittee for Research Animal Studies at the Massachusetts General Hospital.

Reagents. Sodium nitroprusside (SNP) and cycloheximide were purchased from Sigma Chemical Co. (St. Louis, MO). $S$-nitroso-glutathione (GSNO) and spermine NONOate were obtained from Alexis Corp. (San Diego, CA). Oxidized and reduced glutathione, $S$-nitroso-acetylpenicillamine (SNAP), $1 \mathrm{H}$-[1,2,4]oxadiazolo[4,3-a] quinoxalin-1-one (ODQ), and actinomycin D were obtained from Calbiochem-Novabiochem Corp. (La Jolla, CA).

Cultured cells. Cultures of primary RPaSMC were prepared from explants of endothelium- and adventitia-stripped pulmonary arteries of adult Sprague-Dawley rats, as described by $\mathrm{Yu}$ et al. (13). RPaSMC were maintained in RPMI supplemented with $10 \%$ NuSerum (Collaborative Biomedical Products, Bedford, MA), penicillin, and streptomycin. Cells were used between passages 5 and 10 .

RNA blot hybridization. RNA was extracted from RPaSMC using the guanidine isothiocyanate-cesium chloride method, as described previously (14). $10 \mu \mathrm{g}$ of total cellular RNA were fractionated in $1.3 \%$ agarose-formaldehyde gels containing ethidium bromide. RNA was transferred to MAGNA CHARGE membranes (Micron Separations Inc., Westboro, MA) and cross-linked by exposure to ultraviolet light. Membranes were hybridized with rat sGC $\alpha 1$ and $\beta 1$ subunit cDNA probes, as described previously (14) (cDNAs encoding sGC $\alpha 1$ and $\beta 1$ subunits were generously provided by M. Nakane, Abbott Laboratories, Inc., Abbott Park, IL) (5). For some experiments, RNA blots were also hybridized with radiolabeled probes derived from a cDNA encoding the human glyceraldehyde-3-phosphate dehydrogenase (GAPDH; kindly provided by M. Alexander-Bridges, Howard Hughes Medical Institute, Massachusetts General Hospital) (15) and a cDNA encoding rat c-jun (kindly provided by T. Curran, Roche Institute of Molecular Biology, Nutley, NJ) (16). Membranes were also hybridized with a 15 -fold molar excess of a ${ }^{32} \mathrm{P}$-labeled oligonucleotide complementary to rat $18 \mathrm{~S}$ RNA (17). Because ribosomal RNA represents the vast majority of cellular RNA and 18S RNA is a fixed proportion of ribosomal RNA, hybridization of this oligonucleotide was used as a measure for each sample of the quantity of total RNA loaded on gels.

Measuring $s G C$ subunit protein levels in RPaSMC. RPaSMC were homogenized in buffer containing $50 \mathrm{mM}$ Tris-HCl, pH 7.6, $1 \mathrm{mM}$ EDTA, $1 \mathrm{mM}$ DTT, and $2 \mathrm{mM}$ PMSF. Extracts were centrifuged at $100,000 \mathrm{~g}$ for $1 \mathrm{~h}$ at $4^{\circ} \mathrm{C}$. Supernatants $(30 \mu \mathrm{g})$ of centrifuged cell extracts were fractionated using $8 \%$ SDS-PAGE and transferred to nitrocellulose filters (Micron Separations Inc.). Filters were blocked at room temperature for $1 \mathrm{~h}$ in phosphate-buffered saline, $\mathrm{pH} \mathrm{7.4,} \mathrm{con-}$ taining 5\% nonfat dry milk (PBS-milk), and then incubated at room temperature for $1 \mathrm{~h}$ with an immunoaffinity-purified polyclonal antiserum directed against the sGC $\beta 1$ subunit (prepared as described below). Bound antibody was detected by incubation of the filters with horseradish peroxidase protein A (Boehringer Mannheim Biochemicals, Indianapolis, IN) and visualized using chemiluminescence (Enhanced Chemiluminescence Kit; Amersham Life Sciences, Arlington Heights, IL) and exposure to x-ray film. Selected filters were also incubated with a monoclonal antiserum directed against the sGC $\alpha 1$ subunit (18) (kindly provided by M. Nakane), diluted 1:500 in PBSmilk. Bound antibodies were detected by incubation of filters with horseradish peroxidase-labeled goat anti-mouse immunoglobulin (Amersham Life Sciences) and were visualized using chemiluminescence. Films were scanned using a Color Image Scanner (Seiko Epson Corp., Tokyo, Japan) and the National Institutes of Health Image 1.44 software. sGC subunit concentrations were estimated by measuring the absorbance on $\mathrm{x}$-ray films corresponding to each sGC subunit.

To prepare an antiserum directed against the sGC $\beta 1$ subunit, a Pst1 restriction fragment of the $\beta 1$ subunit cDNA was ligated into the prokaryotic expression plasmid pMAL-c2 (New England Biolabs Inc., Beverly, MA) and the plasmid was used to transform Escherichia coli. A fusion protein containing maltose-binding protein and amino acids $67-377$ of the rat sGC $\beta 1$ subunit was purified by column chromatography. Purified fusion protein emulsified in complete Freund's adjuvant was injected intradermally into rabbits. At monthly intervals, animals were injected intramuscularly with fusion protein emulsified in incomplete Freund's adjuvant. Anti- $\beta 1$ subunit antibodies were immunoaffinity-purified from rabbit sera using a glutathione- $S$-transferase (GST)- $\beta 1$ subunit fusion protein (19). To prepare this fusion protein, the Pst1 restriction fragment of the $\beta 1$ subunit cDNA was ligated into the prokaryotic expression vector pGEX-KG (20), and the plasmid was used to transform E. coli. Bacterial extract containing the GST- $\beta 1$ subunit fusion protein was fractionated using SDS-PAGE and transferred to a nitrocellulose membrane as described above. The membrane was blocked in PBS containing $5 \%$ nonfat dry milk at $50^{\circ} \mathrm{C}$ for $1 \mathrm{~h}$ and was then incubated with serum from rabbits immunized with the maltose-binding protein- $\beta 1$ subunit fusion protein (diluted 1:10 in blocking solution) for $1 \mathrm{~h}$ at room temperature. Bound antibodies were eluted by incubation in $100 \mathrm{mM}$ glycine- $\mathrm{HCl}, \mathrm{pH} 2.5$, for $10 \mathrm{~min}$ at room temperature. The antibody solution was neutralized by the addition of $1 \mathrm{M}$ Tris buffer, $\mathrm{pH}$ 8.8. Affinity-purified antibodies were concentrated using an Amicon concentrator (W.R. Grace and Co., Beverly, MA).

Soluble guanylate cyclase enzyme activity. sGC enzyme activity was measured as described by Mittal (21). RPaSMC supernatants $(30 \mu \mathrm{g})$ were incubated for $10 \mathrm{~min}$ at $37^{\circ} \mathrm{C}$ in a reaction mixture containing $50 \mathrm{mM}$ Tris- $\mathrm{HCl}, \mathrm{pH} 7.5,4 \mathrm{mM} \mathrm{MgCl} 2,0.5 \mathrm{mM}$ 1-methyl-3-isobutylxanthine, $7.5 \mathrm{mM}$ creatine phosphate, $0.2 \mathrm{mg} / \mathrm{ml}$ creatine phosphokinase, and $1 \mathrm{mM}$ GTP with and without $1 \mathrm{mM}$ sodium nitroprusside. The reaction was terminated by addition of $0.9 \mathrm{ml} 0.05 \mathrm{~N} \mathrm{HCl}$ and boiling for $3 \mathrm{~min}$. cGMP in the reaction mixture was measured using a commercial RIA (Biomedical Technologies, Inc., Stoughton, MA). sGC enzyme activity is expressed as picomoles of cGMP produced per minute per milligram protein in the cell supernatant (mean $\pm S D$ ). sGC enzyme activities were compared by a factorial model of analysis of variance. When significant differences were detected, Scheffe's analysis was used post hoc to compare groups. Significance was declared if $P<0.05$.

\section{Results}

Exposure of rat pulmonary artery smooth muscle cells to $\mathrm{NO}$ donor compounds decreases $s G C$ subunit $m R N A$ and protein levels. To investigate the effect of exposure to $\mathrm{NO}$ on sGC subunit gene expression, RPaSMC were incubated with $\mathrm{NO}$ donor compounds, and the levels of mRNAs encoding sGC subunits were measured by RNA blot hybridization. Exposure of RPaSMC for $4 \mathrm{~h}$ to SNP decreased $\mathrm{sGC} \alpha 1$ and $\beta 1$ subunit mRNA levels in a dose-dependent manner (Fig. 1). Concentrations $\geq 10 \mu \mathrm{M}$ SNP consistently decreased sGC subunit mRNA levels. The magnitude of the decrease in sGC subunit mRNA levels in RPaSMC exposed to SNP was dependent on the duration of exposure to SNP: minimum sGC subunit mRNA levels were evident after $4 \mathrm{~h}$ of exposure to SNP, and levels remained low for up to $24 \mathrm{~h}$. Exposure of RPaSMC for $4 \mathrm{~h}$ to other NO donor compounds including GSNO and SNAP (Fig. 2), as well as spermine NONOate (data not shown), also decreased sGC subunit mRNA levels. Concentrations of GSNO and SNAP $\geq 1$ and $10 \mu \mathrm{M}$, respectively, decreased sGC subunit mRNA levels (Fig. 2). By-products of NO generation from SNP and GSNO, cyanide and glutathione, respectively, did not alter sGC subunit mRNA levels (Fig. 2). These results suggest that $\mathrm{NO}$ generation by $\mathrm{NO}$ donor compounds was responsible for the observed effects on sGC subunit gene expression. Exposure of RPaSMC for $24 \mathrm{~h}$ to $1 \mathrm{mM}$ SNP or $100 \mu \mathrm{M}$ GSNO did not induce cell toxicity. The percentage of cells that failed to exclude trypan blue did not differ in 

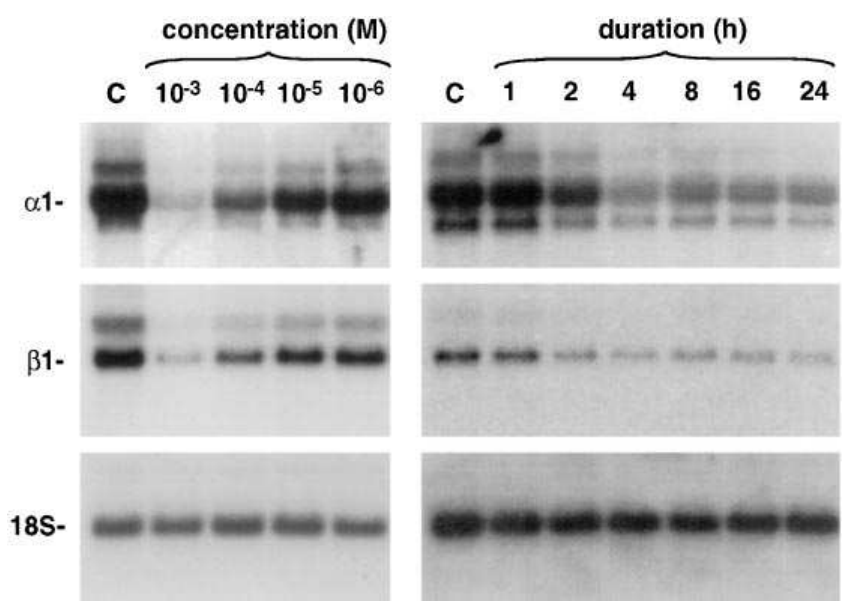

Figure 1. NO decreases sGC subunit mRNA levels in rat pulmonary artery smooth muscle cells. RNA extracted from RPaSMC exposed to $10^{-6}$ to $10^{-3} \mathrm{M}$ SNP for $4 \mathrm{~h}$, from RPaSMC exposed to $1 \mathrm{mM} \mathrm{SNP}$ for $1,2,4,8,16$, and $24 \mathrm{~h}$, and from untreated RPaSMC $(C)$ was fractionated on formaldehyde-agarose gels, transferred to nylon membranes, and hybridized with sGC $\alpha 1$ and $\beta 1$ subunit cDNA probes and with an oligonucleotide complementary to $18 \mathrm{~S}$ ribosomal RNA. (The band below the $\alpha 1$ subunit mRNA represents residual signal from the earlier hybridization with the $\beta 1$ subunit cDNA probe.) These results demonstrate that the NO-mediated decrease in sGC subunit mRNA levels is exposure duration and dose dependent.

$\mathrm{RPaSMC}$ incubated in the presence or absence of an NO donor compound and was $<1 \%$ for both.

To determine whether NO-mediated changes in sGC subunit gene expression were correlated with changes in subunit protein levels, sGC $\beta 1$ subunit levels were measured in RPaSMC exposed to $1 \mathrm{mM} \mathrm{SNP}$ for 4, 8, and $24 \mathrm{~h}$ (Fig. 3, top). Levels of the sGC $\beta 1$ subunit progressively decreased in RPaSMC exposed to SNP with a half-life between 4 and $8 \mathrm{~h}$. In cells exposed to SNP for $24 \mathrm{~h}$, sGC subunit levels were $<10 \%$ of that in control cells. The effect of SNP on sGC $\beta 1$ subunit levels was dose dependent: incubation of RPaSMC with as little as $10 \mu \mathrm{M}$ SNP decreased $\beta 1$ subunit concentrations (Fig. 3,

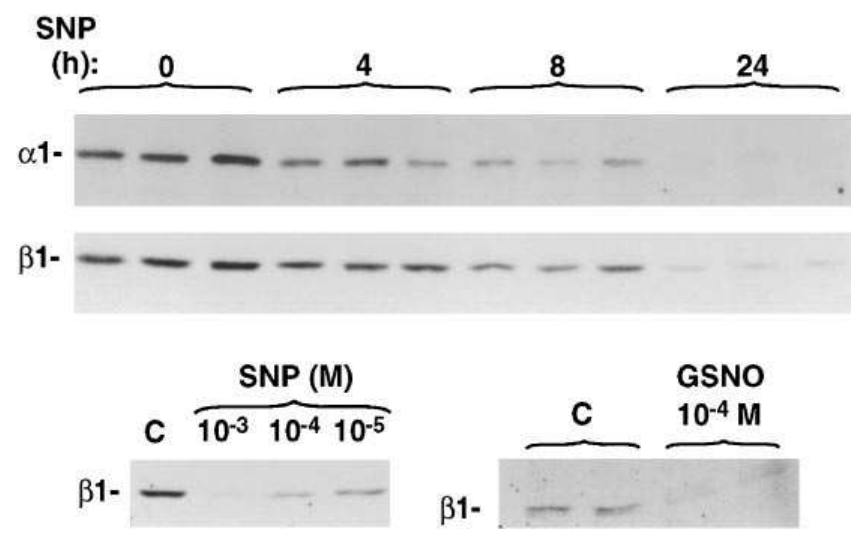

Figure 3. NO decreases sGC subunit protein levels in rat pulmonary artery smooth muscle cells. sGC $\alpha 1$ and $\beta 1$ subunit levels were measured in RPaSMC exposed to $1 \mathrm{mM}$ SNP for $0,4,8$, and $24 \mathrm{~h}$ (top). sGC $\beta 1$ subunit levels were also measured in RPaSMC incubated for $24 \mathrm{~h}$ in the absence $(C)$ or presence of $10^{-5}$ to $10^{-3} \mathrm{M} \mathrm{SNP}$ (lower left) and $10^{-4} \mathrm{M}$ GSNO (lower right). Proteins in the soluble fraction of cell extracts were fractionated using SDS-PAGE and transferred to nitrocellulose. Immunoreactive sGC $\beta 1$ subunit $(70 \mathrm{kD})$ was detected using an immunoaffinity-purified polyclonal antibody directed against the $\beta 1$ subunit. Immunoreactive $\mathrm{sGC} \alpha 1$ subunit $(82 \mathrm{kD})$ was detected using a monoclonal antibody directed against the $\alpha 1$ subunit. These results demonstrate that sGC subunit protein levels decrease in RPaSMC exposed to NO.

bottom left). Incubation of RPaSMC with $100 \mu \mathrm{M}$ GSNO also decreased sGC $\beta 1$ subunit levels (Fig. 3, bottom right). Using a monoclonal antibody directed against the rat $\mathrm{sGC} \alpha 1$ subunit, $\alpha 1$ subunit levels were found to decrease in cells exposed to SNP in parallel with $\beta 1$ subunit levels (Fig. 3, top). These results demonstrate that chronic exposure of RPaSMC to NO donor compounds decreases $\mathrm{sGC}$ subunit mRNA and protein levels.

Exposure of rat pulmonary artery smooth muscle cells to $N O$ donor compounds decreases $s G C$ enzyme activity. To determine the effect of chronic NO exposure on sGC function, $\mathrm{RPaSMC}$ were exposed to $1 \mathrm{mM} \mathrm{SNP}$ for 4,8 , and $24 \mathrm{~h}$, and

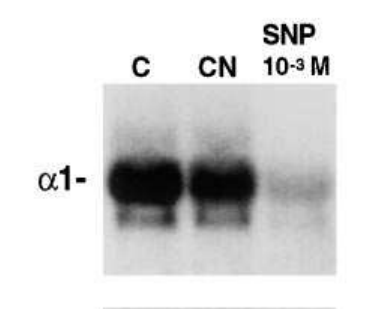

$\beta 1-$

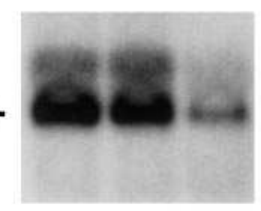

18S-

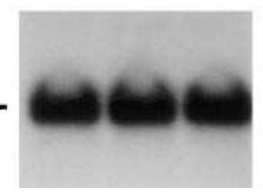

SNAP
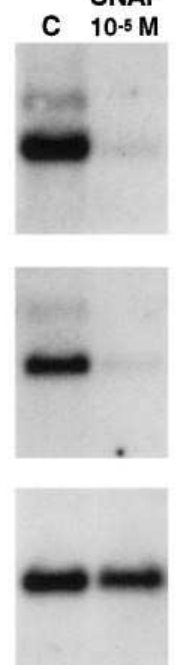

GSNO
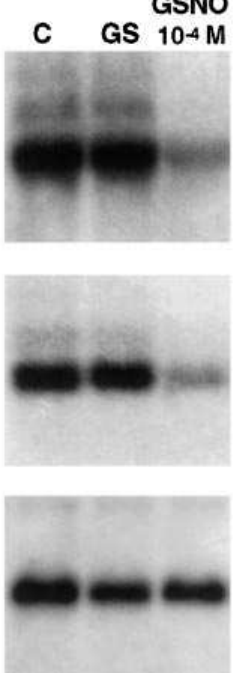

GSNO (M)
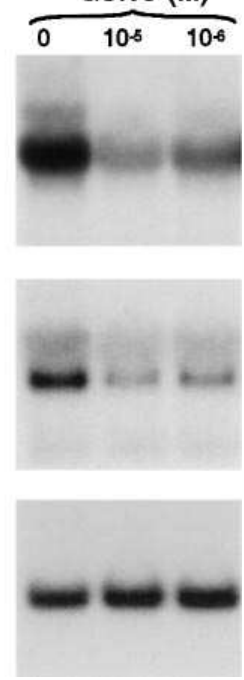

Figure 2. NO generation by NO donor compounds decreases sGC subunit mRNA levels. RPaSMC were incubated for $4 \mathrm{~h}$ in the absence $(C)$ and presence of $10^{-3} \mathrm{M} \mathrm{SNP}, 10^{-3} \mathrm{M}$ sodium cyanide $(C N), 10^{-5} \mathrm{M} \mathrm{SNAP}, 10^{-6}$ to $10^{-4} \mathrm{M} S$-nitroso-glutathione (GSNO), and $10^{-4} \mathrm{M}$ oxidized glutathione (GS). RNA blots were prepared and hybridized with $\mathrm{sGC} \alpha 1$ and $\beta 1$ subunit cDNA probes and with an oligonucleotide complementary to $18 \mathrm{~S}$ ribosomal RNA. These results suggest that sGC subunit mRNA levels decrease in response to the generation of NO from NO donor compounds. 


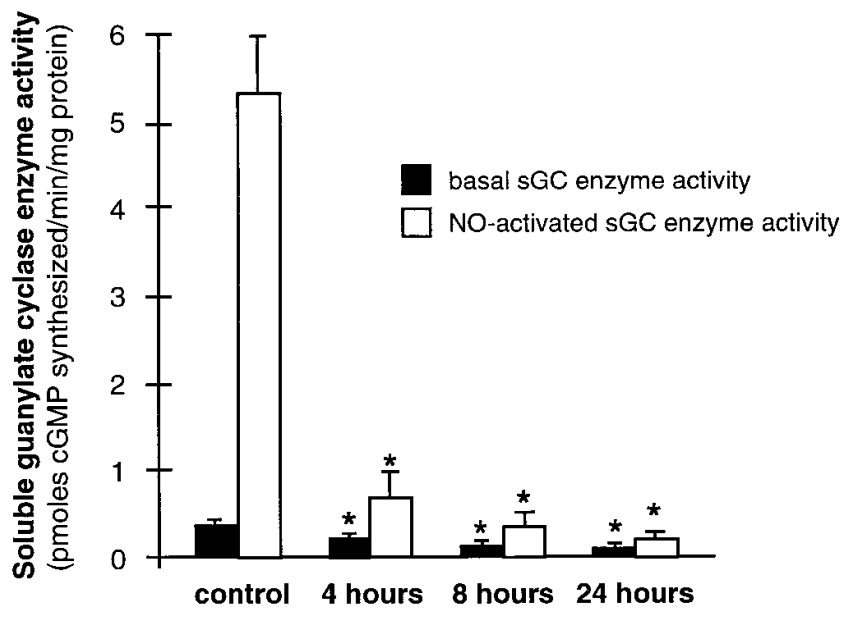

Figure 4. sGC enzyme activity is decreased in rat pulmonary artery smooth muscle cells chronically exposed to NO. The soluble fraction of extracts derived from untreated RPaSMC (control) and RPaSMC exposed to $1 \mathrm{mM} \mathrm{SNP}$ for 4,8 , and $24 \mathrm{~h}$ (three separate experiments for each time point) was assayed for sGC enzyme activity in the absence (closed boxes) and presence (open boxes) of $1 \mathrm{mM} \mathrm{SNP.} \mathrm{sGC}$ enzyme activity is expressed as picomoles of cGMP produced per minute per milligram of cell extract supernatant $( \pm S D)$. *Significant differences from control values $(P<0.01)$. These results show that basal and NO-activated sGC enzyme activity is reduced in RPaSMC chronically exposed to NO.

sGC enzyme activity was measured in the soluble fraction of cell extracts (Fig. 4). In extracts prepared from untreated RPaSMC, addition of SNP to the reaction mixture increased sGC enzyme activity $>10$-fold (from $0.38 \pm 0.07$ to $5.4 \pm 0.58$ pmol cGMP synthesized per min/mg protein). In extracts prepared from cells exposed to SNP for $4 \mathrm{~h}$, basal and NO-stimulated sGC enzyme activity decreased by 47 and $87 \%$, respectively $(0.20 \pm 0.05$ and $0.68 \pm 0.26 ; P<0.01$ for both). Similar decreases in basal and NO-stimulated sGC enzyme activity were observed in RPaSMC exposed for $4 \mathrm{~h}$ to $100 \mu \mathrm{M}$ GSNO (data not shown). NO-activated sGC enzyme activity in RPaSMC exposed to SNP for $24 \mathrm{~h}$ was $<5 \%$ of that in control cells. These results demonstrate that chronic exposure to NO decreases the capacity of RPaSMC to synthesize cGMP.

Regulation of soluble guanylate cyclase subunit gene expression by NO is mediated by a cGMP-dependent mechanism. To investigate the mechanisms responsible for the effect of $\mathrm{NO}$ on sGC subunit gene expression, RPaSMC were treated with $3 \mu \mathrm{M}$ ODQ, an inhibitor of sGC, before exposure to SNP. Pretreatment with ODQ nearly completely blocked the ability of SNP to decrease sGC subunit gene expression (Fig. 5). To further investigate whether the sGC enzyme product cGMP could modulate sGC subunit gene expression, RPaSMC were incubated with the membrane-permeable cGMP analogue, 8-bromo cGMP. Exposure of RPaSMC to 1 $\mathrm{mM} 8$-bromo cGMP for $4 \mathrm{~h}$ decreased $\mathrm{sGC} \alpha 1$ and $\beta 1$ subunit mRNA levels (Fig. 5). These results suggest that the effect of $\mathrm{NO}$ on sGC subunit gene expression is mediated by a cGMPdependent mechanism.

Nitric oxide decreases soluble guanylate cyclase subunit $m R N A$ stability. Exposure of RPaSMC to NO decreased levels of mRNAs encoding sGC $\alpha 1$ and $\beta 1$ subunits. To deter-

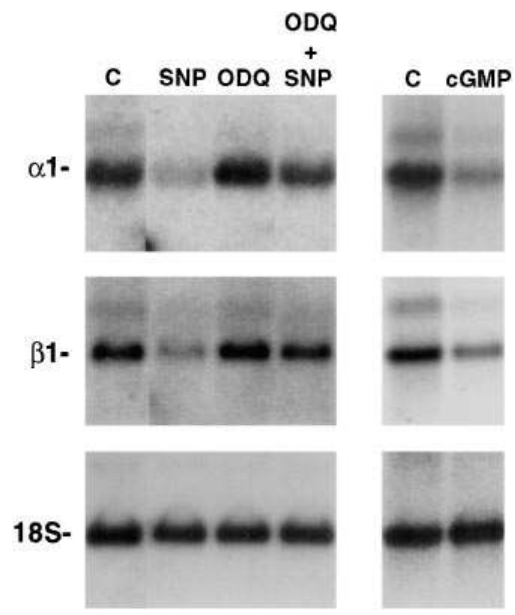

Figure 5. NO decreases sGC subunit mRNA levels via a cGMPdependent mechanism. RPaSMC were incubated with $3 \mu \mathrm{M}$ ODQ, an sGC inhibitor, for $30 \mathrm{~min}$, and then were exposed to $1 \mathrm{mM}$ SNP for $4 \mathrm{~h}$. Other RPaSMC were untreated $(C)$ or were incubated with either SNP, ODQ, or $1 \mathrm{mM}$ 8-bromo cGMP $(c G M P)$ alone. RNA extracted from RPaSMC was hybridized with $\alpha 1$ and $\beta 1$ subunit cDNA probes and

the oligonucleotide complementary to $18 \mathrm{~S}$ RNA. The decrease in sGC subunit mRNA levels detected in cells exposed to 8-bromo cGMP but not in cells exposed to the combination of SNP and ODQ suggests that $\mathrm{NO}$ decreases $\mathrm{sGC}$ subunit gene expression via a cGMP-dependent mechanism.

mine if altered mRNA transcription or stability contributed to the NO-mediated decrease in sGC subunit mRNA levels, the effect of actinomycin D, an RNA polymerase inhibitor, on sGC subunit gene expression was measured in RPaSMC incubated in the presence or absence of SNP. In RPaSMC exposed to $10 \mu \mathrm{M}$ actinomycin $\mathrm{D}$ for up to $6 \mathrm{~h}$, the levels of sGC $\alpha 1$ and $\beta 1$ subunit mRNAs were unchanged (Fig. $6 A$ ). In RPaSMC incubated in the presence of SNP, the levels of sGC $\alpha 1$ and $\beta 1$ subunit mRNAs decreased markedly within $4 \mathrm{~h}$. Incubation of RPaSMC with actinomycin D blocked the ability of SNP to decrease sGC subunit mRNA levels. An mRNA with a short half-life, c-jun, was detected in control and SNP-treated RPaSMC, but not in actinomycin D-treated cells, demonstrating that the concentration of actinomycin D used was sufficient to block gene transcription in RPaSMC. Levels of the mRNA encoding glyceraldehyde-3-phosphate dehydrogenase, an mRNA with a long half-life, were not altered by exposure of RPaSMC for up to $6 \mathrm{~h}$ to actinomycin D, SNP, or the combination (Fig. 6 $A)$. These results demonstrated that SNP did not decrease levels of all mRNAs. Incubation of RPaSMC with the protein synthesis inhibitor cycloheximide $(100 \mu \mathrm{M})$ also prevented the NO-induced decrease in sGC subunit mRNA levels (Fig. $6 B$ ). In additional studies, actinomycin $\mathrm{D}$ and cycloheximide were found to block the effect of GSNO on sGC subunit gene expression, and sGC subunit mRNA levels decreased more rapidly in GSNO-treated RPaSMC than in actinomycin D-treated cells (data not shown). These results suggest that NO decreases the stability of sGC subunit mRNAs selectively via a mechanism that is both transcription and translation dependent.

\section{Discussion}

Exposure of rat pulmonary artery smooth muscle cells to NO donor compounds decreased expression of genes encoding both the $\alpha 1$ and $\beta 1$ subunits of the heterodimeric sGC enzyme. Diminished sGC subunit gene expression was accompanied by 


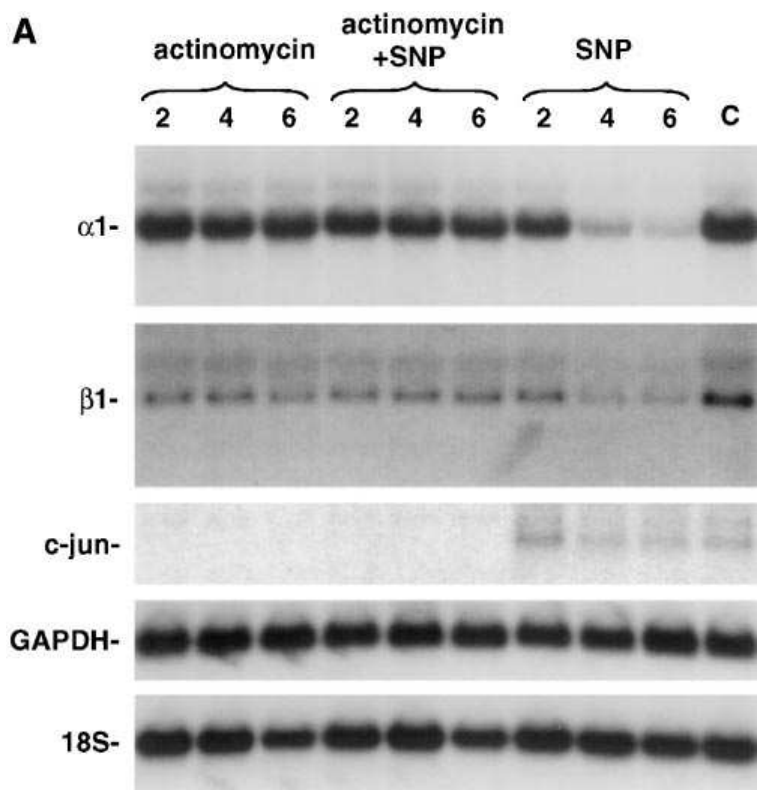

B

$\alpha 1-$

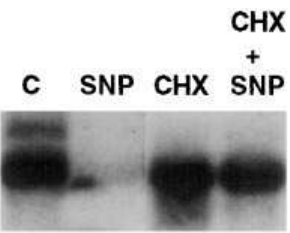

$\beta 1-$

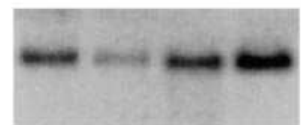

18S-

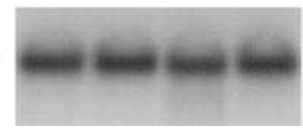

Figure 6. Inhibition of gene transcription or protein synthesis blocks the ability of NO to decrease sGC subunit mRNA levels. (A) RPaSMC were pretreated with $10 \mu \mathrm{M}$ actinomycin $\mathrm{D}$ for $30 \mathrm{~min}$, and then were exposed to $1 \mathrm{mM} \mathrm{SNP}$ for 2,4 , and $6 \mathrm{~h}$. Other cells were treated with actinomycin D alone, SNP alone, or were untreated $(C)$. RNA extracted from RPaSMC was hybridized with $\alpha 1$ and $\beta 1$ subunit, c-jun, and GAPDH cDNA probes, and with an oligonucleotide complementary to $18 \mathrm{~S}$ RNA. These results show that the NO-induced decrease in SGC subunit mRNA levels is selective and actinomycin D sensitive. (B) RPaSMC were pretreated with $100 \mu \mathrm{M}$ cycloheximide $(\mathrm{CHX})$ for $30 \mathrm{~min}$, and then were exposed to $1 \mathrm{mM} \mathrm{SNP}$ for $4 \mathrm{~h}$. Other cells were untreated $(C)$ or were treated with cycloheximide or SNP alone. RNA extracted from RPaSMC was hybridized with $\alpha 1$ and $\beta 1$ subunit cDNA probes and an oligonucleotide complementary to $18 \mathrm{~S}$ RNA. These results demonstrate that the NO-induced decrease in sGC subunit mRNA levels is cycloheximide sensitive. decreased subunit protein levels and decreased basal and NOactivated sGC enzyme activity. The concentrations of NO donor compounds used in this study are comparable with those required to modulate expression of genes encoding other proteins, including endothelin 1 (8), macrophage-colony stimulating factor (22), and the endothelin A receptor (23). Experiments using NO synthase inhibitors demonstrated that levels of NO sufficient to modulate expression of these genes are attainable in endothelial cells $(8,22)$ and in cytokine-treated smooth muscle cells (23). Moreover, using an NO-selective electrode, Ichimori et al. observed that concentrations of NO generated by $10 \mu \mathrm{M}$ SNAP in biological fluids are similar to those produced by endothelial cells stimulated with $1 \mu \mathrm{M}$ acetylcholine (24). Taken together, these observations suggest that concentrations of NO sufficient to alter sGC subunit mRNA levels are attainable in vivo.

Exposure of RPaSMC to a membrane-permeable cGMP analogue, 8-bromo cGMP, decreased sGC subunit gene expression, whereas an inhibitor of sGC enzyme activity, ODQ, attenuated the ability of NO to alter sGC subunit mRNA levels. These results suggest that the effect of NO on sGC subunit gene expression is cGMP dependent. Other investigators have also suggested that cGMP regulates sGC subunit gene expression. Ujiie et al. (25) observed that incubation of cultured rat medullary interstitial cells with agents that increased intracellular cGMP concentrations decreased sGC enzyme activity and that exposure of these cells to $0.3 \mathrm{mM}$ SNP modestly decreased sGC $\alpha 1$ and $\beta 1$ subunit mRNA levels. Similarly, Papapetropoulos et al. (26) observed that incubation of aortic smooth muscle cells with Zaprinast, an inhibitor of cGMP degradation by type 5 phosphodiesterase, decreased sGC subunit gene expression. Increased cGMP levels may alter sGC subunit gene expression via activation of cGMP-dependent protein kinase. Alternatively, cGMP may inhibit phosphodiesterase activity (27), leading to increased cAMP levels that in turn may decrease sGC subunit mRNA levels, as described previously in other cell types (28-30).

Nitric oxide appears to decrease sGC subunit mRNA stability via a transcription-dependent mechanism. This conclusion is based on the observations that sGC subunit mRNA levels decrease more rapidly in RPaSMC exposed to NO than in cells exposed to actinomycin $\mathrm{D}$ and that pretreatment of RPaSMC with actinomycin D blocked the ability of NO to alter sGC subunit mRNA levels. The observations that levels of c-jun and GAPDH mRNAs did not change markedly in RPaSMC exposed to SNP are consistent with NO mediating a selective effect on $\mathrm{sGC}$ subunit mRNAs. Incubation of $\mathrm{RPaSMC}$ with the protein synthesis inhibitor cycloheximide also blocked the ability of NO to decrease sGC subunit mRNA levels, supporting the hypothesis that NO induces synthesis of an mRNA destabilizing protein. However, it should be noted that, for some mRNAs, low levels of mRNA translation are required for the degradation of the molecule (31). We recently reported that incubation of $\mathrm{PC} 12$ cells with nerve growth factor decreases SGC subunit mRNA levels via a similar transcription- and translation-dependent mechanism (30). These observations suggest that shared regulatory mechanisms may control sGC subunit gene expression in these two cell types.

NO-induced modulation of mRNA stability has been reported previously. Pantopoulos and Hentze (12) observed that NO stabilized the mRNA encoding the transferrin receptor by activating binding of an iron-regulatory protein (IRP) to sequences (iron-response elements, IREs) in the $3^{\prime}$ untranslated region of the mRNA. It is unlikely that the IRP/IRE system (reviewed in reference 32) is responsible for the effect of NO on sGC subunit mRNA stability because IRP/IRE modulation of mRNA stability does not require gene transcription and consensus IRE sequences are absent from the reported sequences of the mRNAs encoding $\alpha 1$ and $\beta 1$ subunits (5). The 
NO-mediated transcription/translation-dependent destabilization of sGC subunit mRNAs appears to represent a novel mechanism by which NO modulates gene expression.

Chronic exposure of RPaSMC to SNP decreased sGC enzyme activity. However, whereas NO-activated sGC enzyme activity decreased $87 \%$ within $4 \mathrm{~h}$, more than $4 \mathrm{~h}$ were required to decrease sGC subunit protein levels by $50 \%$. These results suggest that chronic exposure to $\mathrm{NO}$ donor compounds decreases the specific activity of the sGC enzyme, as well as the levels of its subunits. Mechanisms regulating the specific activity of the sGC enzyme have been extensively investigated (reviewed in reference 27). Other investigators have observed that chronic exposure of cultured vascular smooth muscle cells decreased sGC enzyme activity $(26,33)$. Papapetropoulos et al. (26) observed that pretreatment with reducing agents such as ascorbic acid restored NO-stimulated cGMP synthesis in RPaSMC chronically exposed to SNP and suggested that chronic exposure to NO may impair sGC enzyme activity by altering the redox state of the enzyme.

The decrease in sGC enzyme activity associated with chronic exposure to NO may have important clinical implications. Downregulation of sGC function may have a protective effect under conditions associated with elevated NO levels. For example, cells respond to viral, bacterial, or parasitic infection by producing high concentrations of NO (1). It is possible that NO-mediated downregulation of sGC function represents a homeostatic mechanism preventing excessive activation of cGMP-dependent protein kinase and other cGMP-dependent mechanisms and, thereby, attenuating NO-mediated host cell toxicity or hemodynamic compromise. Chronic administration of NO donor compounds, such as nitroglycerin, impairs the ability of vascular smooth muscle to respond to additional NO. Clinically, this phenomenon, referred to as nitrate tolerance, is important for patients with coronary artery disease to whom nitroglycerin is chronically administered. The etiology of nitrate tolerance is multifactorial (34) with decreased sGC enzyme activity having an important role $(35,36)$. Although the concentrations of NO donor compounds required to elicit nitrate tolerance are typically greater in cultured cells than in vivo, the observations presented here suggest that decreased sGC subunit mRNA levels may contribute to impaired NO responsiveness in nitrate tolerance.

In summary, chronic exposure of rat pulmonary artery smooth muscle cells to NO donor compounds decreased sGC subunit mRNA and protein levels and decreased sGC enzyme activity. The NO-induced decrease in the levels of mRNAs encoding both sGC subunits was cGMP, actinomycin D, and cycloheximide dependent. These results suggest that NO induces synthesis of a factor (probably a protein) that selectively destabilizes sGC subunit mRNAs. NO-induced modulation of sGC subunit mRNA levels illustrates a novel mechanism by which NO regulates gene expression.

\section{Acknowledgments}

The authors thank Dr. M. Nakane for providing the sGC subunit cDNAs and the monoclonal antibody directed against the sGC $\alpha 1$ subunit, Dr. M. Alexander-Bridges for providing the human glyceraldehyde-3-phosphate dehydrogenase cDNA probe, and Dr. T. Curran for providing the c-jun cDNA probe. The authors also thank Drs. H. Liu, M. Takata, and K.J. Bloch for their review of this manuscript.

This work was supported by National Institutes of Health grants
HL-55377 (K.D. Bloch), AR-01866 (D.B. Bloch), and DK-51179 (D.B. Bloch), by an Arthritis Investigator Award from the Arthritis Foundation (D.B. Bloch), and by a grant to the Cardiovascular Research Center from Bristol Myers Squibb Pharmaceuticals. K.D. Bloch is an Established Investigator of the American Heart Association.

\section{References}

1. Schmidt, H.H.H.W., and U. Walter. 1994. NO at work. Cell. 78:919-925.

2. Cobb, J.P., and R.L. Danner. 1996. Nitric oxide and septic shock. JAMA (J. Am. Med. Assoc.). 275:1192-1196.

3. Lincoln, T.M., and T.L. Cornwell. 1993. Intracellular cyclic GMP receptor proteins. FASEB J. 7:328-338.

4. Wong, S.K.-F., and D.L. Garbers. 1992. Receptor guanylyl cyclases. J. Clin. Invest. 90:299-305.

5. Nakane, M., K. Arai, S. Saheki, T. Kuno, W. Buechler, and F. Murad. 1990. Molecular cloning and expression of cDNAs coding for soluble guanylate cyclase from rat lung. J. Biol. Chem. 265:16841-16845.

6. Peunova, N., and G. Enikolopov. 1993. Amplification of calcium-induced gene transcription by nitric oxide in neuronal cells. Nature (Lond.). 364:450 453 .

7. Pilz, R.B., M. Suhasini, S. Idress, J.L. Meinkoth, and G.R. Boss. 1995. Nitric oxide and cGMP analogs activate transcription from AP-1-responsive promoters in mammalian cells. FASEB J. 9:552-558.

8. Kourembanas, S., L.P. McQuillan, G.K. Leung, and D.V. Faller. 1993. Nitric oxide regulates the expression of vasoconstrictors and growth factors by vascular endothelium under both normoxia and hypoxia. J. Clin. Invest. 92:99104.

9. DeCatarina, R., P. Libby, H.-B. Peng, V.J. Thannickai, T.B. Rajavashisth, M.A. Gimbrone, W.S. Shin, and J.K. Liao. 1995. Nitric oxide decreases cytokine-induced endothelial activation. J. Clin. Invest. 96:60-68.

10. Shin, W.S., Y.-H. Hong, H.-B. Peng, R. DeCatarina, P. Libby, and J.K. Liao. 1996. Nitric oxide attenuates vascular smooth muscle cell activation by interferon- $\gamma$. J. Biol. Chem. 271:11317-11324.

11. Peng, H.-B., P. Libby, and J.K. Liao. 1995. Induction and stabilization of

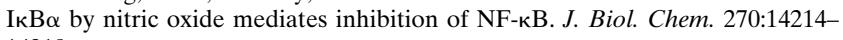
14219.

12. Pantopoulos, K., and M.W. Hentze. 1995. Nitric oxide signaling to ironregulatory protein: direct control of ferritin mRNA translation and transferrin receptor mRNA stability in transfected fibroblasts. Proc. Natl. Acad. Sci. USA. 92:1267-1271.

13. Yu, F.-S., S.-L. Lee, J.J. Lanzillo, and B.L. Fanburg. 1989. Endothelial cell inhibition of hypoxia-induced stimulation of serotonin uptake by vascular smooth muscle cells. Am. Rev. Respir. Dis. 138:1144-1148.

14. Bloch, K.D., G. Filippov, L.S. Sanchez, M. Nakane, and S.M. de la Monte. 1997. Expression of soluble guanylate cyclase, a nitric oxide receptor, is regulated during pulmonary development. Am. J. Physiol. 272:L400-L406.

15. Ercolani, L., B. Florence, M. Denaro, and M. Alexander. 1988. Isolation and complete sequence of a functional human glyceraldehyde-3-phosphate dehydrogenase gene. J. Biol. Chem. 263:15335-15341.

16. Abate, C., D. Luk, and T. Curran. 1991. Transcriptional regulation by Fos and Jun in vitro: interaction among multiple activator and regulatory domains. Mol. Cell. Biol. 11:3624-3632.

17. Lee, R.T., K.D. Bloch, J.M. Pfeffer, M.A. Pfeffer, E.J. Neer, and C.E. Seidman. 1988. Atrial natriuretic factor gene expression in ventricles of rats with spontaneous biventricular hypertrophy. J. Clin. Invest. 81:431-434.

18. Kamisaki, Y., S. Saheki, M. Nakane, J.A. Palmieri, T. Kuno, B.Y. Chang, S.A. Waldman, and F. Murad. 1986. Soluble guanylate cyclase from rat lung exists as a heterodimer. J. Biol. Chem. 261:7236-7241.

19. Olmsted, J.B. 1981. Affinity purification of antibodies from diazotized paper blots of heterogeneous protein samples. J. Biol. Chem. 256:11955-11957.

20. Guan, K.-L., and J.E. Dixon. 1991. Eukaryotic proteins expressed in Escherichia coli: an improved thrombin cleavage and purification procedure of fusion proteins with glutathione-S-transferase. Anal. Biochem. 192:262-267.

21. Mittal, C.K. 1986. Determination of adenylate cyclase and guanylate cyclase activities in cells and immune system. Methods Enzymol. 132:422-428.

22. Peng, H.-B., T.B. Rajavashisth, P. Libby, and J.K. Liao. 1995. Nitric oxide inhibits macrophage-colony stimulating factor gene transcription in vascular endothelial cells. J. Biol. Chem. 270:17050-17055.

23. Redmond, E.M., P.A. Cahill, R. Hodges, S. Zhang, and J.V. Sitzmann. 1996. Regulation of endothelin receptors by nitric oxide in cultured rat vascular smooth muscle cells. J. Cell. Physiol. 166:469-479.

24. Ichimori, K., H. Ishida, F. Fukahori, H. Nakazawa, and E. Murakami. 1994. Practical nitric oxide measurement employing a nitric oxide-selective electrode. Rev. Sci. Instrum. 65:2714-2718.

25. Ujiie, K., L. Hogarth, R. Danziger, J.G. Drewett, P.S.T. Yuen, I.-H. Pang, and R.A. Starr. 1994. Homologous and heterologous desensitization of a guanylyl cyclase-linked nitric oxide receptor in cultured rat medullary interstitial cells. J. Pharmacol. Exp. Ther. 270:761-767. 
26. Papapetropoulos, A., C.Y. Go, F. Murad, and J.D. Catravas. 1996. Mechanisms of tolerance to sodium nitroprusside in rat cultures aortic smooth muscle cells. Br. J. Pharmacol. 117:147-155.

27. Hobbs, A.J., and L.J. Ignarro. 1996. The nitric oxide-cGMP signal transduction system. In Nitric Oxide and the Lung. W.M. Zapol and K.D. Bloch, editors. Lung Biology in Health and Disease. Marcel Dekker Inc., New York. pp. $1-57$.

28. Shimouchi, A., S.P. Janssens, D.B. Bloch, W.M. Zapol, and K.D. Bloch. 1993. Cyclic AMP regulates soluble guanylate cyclase $\beta 1$ subunit gene expression in RFL-6 rat fetal lung fibroblasts. Am. J. Physiol. 265:L456-L461.

29. Papapetropoulos, A., N. Marczin, G. Mora, A. Milici, F. Murad, and J.D. Catravas. 1995. Regulation of vascular smooth muscle soluble guanylate cyclase activity, mRNA, and protein levels by cAMP-elevating agents. Hypertension. 26:696-704.

30. Liu, H., T. Force, and K.D. Bloch. 1997. Nerve growth factor decreases soluble guanylate cyclase in rat pheochromocytoma PC12 cells. J. Biol. Chem.
272:6038-6043.

31. Sachs, A.B. 1993. Messenger RNA degradation in eukaryotes. Cell. 74: 413-421.

32. Klausner, R.D., T.A. Rouault, and J.B. Harford. 1993. Regulating the fate of mRNA: the control of cellular iron metabolism. Cell. 72:19-28.

33. Zhang, L.M., M.R. Castresana, S. Stefansson, and W.H. Newman. 1993. Tolerance to sodium nitroprusside: studies in cultured porcine vascular smooth muscle cells. Anesthesiology. 79:1094-1103.

34. Munzel, T., S. Kurz, T. Heitzer, and D.G. Harrison. 1996. New insights into mechanisms underlying nitrate tolerance. Am. J. Cardiol. 77:24-30.

35. Axelsson, K.L., and R.G. Andersson. 1983. Tolerance towards nitroglycerin, induced in vivo, is correlated to a reduced cGMP response and an alteration in cGMP turnover. Eur. J. Pharmacol. 88:71-79.

36. Schroder, H., D.C. Leitman, B.M. Bennett, S.A. Waldman, and F. Murad. 1988. Glyceryl trinitrate-induced desensitization of guanylate cyclase in cultured rat lung fibroblasts. J. Pharmacol. Exp. Ther. 245:413-418. 